\title{
Call Warrants Impact on Underlying Stocks: The Taiwan Experience
}

\author{
LIU Shu-Ing, LEE Ching-Yi \\ Shih Hsin University, Taipei, Taiwan
}

\begin{abstract}
On the basis of the price, volume and volatility of underlying stocks, this article empirically investigates the impact of 273 Taiwan call warrants on underlying stocks. Discussions by the market risk, depth, tightness and liquidity, changes on underlying stocks due to warrants issuance, are investigated. In this study, the CAPM is applied for evaluating the market risk, the Kyle model for the market depth, the averaged best five bid-ask spread for the market tightness and the averaged turnover rate for the market liquidity. The empirical results indicate that the most significant influence is the market liquidity, the market tightness next; the market risk and market depth are non-significant.
\end{abstract}

Keywords: CAPM, market depth, market liquidity, market tightness, warrants

\section{Introduction}

In order to coordinate the fast growth in the international money market, perfect the financial market, carry on the financial reform, increase the investment and hedge way, the restrictions to the foreign investor to invest stock market are gradually deregulated by the Taiwan Securities and Future Bureau. In 1997, the native Taiwan warrant market was established, which not only provides the investor creating higher profit opportunity by slightly wrestles in a big way, also creates a useful hedging tool. However, its high leverage is favored the investor to regard as an investment tool, more speculative transactions are introduced. This risk will induce asymmetry phenomenon between prices changing of the warrant and the underlying stock.

Under no arbitrage assumption, the option announcing, releasing on the market and maturity, will not theoretically influence the underlying stock prices. Nevertheless, as traders distribute call warrants, they will usually establish hedging position according the changing of underlying stock prices. As the stock price increases, the trader will buy more stocks according to the possible exercising situation. This will enhance the stock price upward tendency, however, the trader will reduce the warrant position as the stock price decreases, thus the stock prices decreasing will be accelerated. Empirical study of this phenomenon will be an interesting research topic.

Former literatures were focused on the event study technique to investigate the existence of abnormal returns of the underlying stock, during a short period around the warrant declaration or issuance date. However, traders established the hedging position for the stock, may cause the warrant influential period been lengthened. To fulfill this purpose, in this study, the investigating period contains ninety trading days before or after the

LIU Shu-Ing, professor, Ph.D., Department of Finance, Shih Hsin University. LEE Ching-Yi, Master, Department of Finance, Shih Hsin University. 
warrant on the market. According to the market risk, depth, tightness and liquidity, the impacts on the price, volume and volatility of the underlying stock are alternatively investigated.

The rest of this paper is organized in order as follows: Firstly, some related literatures are briefly reviewed. Then research methods including, models and testing hypotheses, are presented, and empirical studies investigating the influences in underlying stock prices and volumes, via 273 Taiwan call warrants, are examined. Finally, the conclusion is included.

\section{Literature Review}

Theoretically, in order to control the transaction exposure, the market maker of the optional market should change the holding positions according to the hedging ratio dynamically. Then, due to the long hedging demand of traders, the prices of the underlying stock would be influenced. Haddad and Voorheis (1991) investigated 116 options issued by the NYSE from 1980 to 1989; the results indicated that significantly increases on the turnover and positive abnormal returns at the option declaration day, were founded. Bagella and Becchetti (1998) provided a modified asymmetric information model to investigate some warrant data in Japan market. The volatility of the underlying stock prices could be used to investigate the elastic analysis of the market risk. Empirical study showed that the market risk indicators were slightly enlarged, 500 days before or after the warrants issuance.

Kumar, Sarin and Shastri (1998) analyzed the impact of options listings on the microstructure property of underlying securities. The empirical study of some options traded in the USA or some Asian markets from 1983 to 1989, indicated that option listings improved the quality of the underlying stocks: The bid-ask spreads and volatilities declined and volumes increased. Hernandez-Trillo (1999) investigated warrants traded in the Mexican Stock Exchange from 1985 to 1996, and the results showed that around 20\% to 30\% underlying stock volatilities significantly increased. Urrutia and Vu (2000) discussed the underlying stock effects from 25 options first time traded in the Chicago Option Exchange, from 1985 to 1987. The empirical results indicated that both stock prices and stock volatilities decreased, whereas no significant change in volumes.

Most of the aforementioned research results were utilized the event study method. And empirical results indicated that warrants trading may cause the variations on stock return, market risk, market depth, bid-ask spread or trading volume. In this paper, the impacts of Taiwan call warrants issuance on the underlying stocks via market risk, depth, tightness and liquidity, are carried out. Instead of using the event study method, some statistical formal testing hypothesis procedures are performed under suitable models.

\section{Research Framework}

\section{The Data Structure}

Usually, most security traders will issue warrants of the market blue chips during a short period. To investigate the impacts of issuing call warrant on the underlying stock, the influence derived from warrants issued by different traders should be avoided. Thus, the sampled call warrants should be carefully screened: In this empirical study, the sampled call warrants are not only the first time issued, also, no other call warrant, using the same underlying stock, has been issued before the maturity of the first issued. From the warrant declaration date to warrant on the market, usually traders will take a long hedge position, commonly 6 to 8 consecutive transaction days.

The whole research period will be separated into three parts: The posterior period is designed as 8 trading 
days before the market day plus 82 trading days after the market date, totally 90 trading days. There is a window period, one month, between the prior and posterior period. The prior period is designed as 90 trading days before the window period. Taking Taiwan Cement Corporation (TCC) stock as the example, the first call warrant was issued on October 31, 2003, with the TCC stock as the underlying security. The prior period is from May 19, 2003 to September 23, 2003, totally 90 trading days. The posterior period is from October 22, 2003 to February 25, 2004, 90 trading days in total. From the beginning of the prior period to the end of the posterior period, is called the whole research period.

\section{Market Risk}

During the period from the warrant announcement to issuance on the market, besides traders will take a long hedge position, investors anticipating the rising in stock prices will also buy in stocks. These influences may lead the market risk of stock returns to inevitably be changed. The CAPM is applied to test whether the market risk of stock returns does increase.

Let $R_{i, t}$ denote the $i$-th company stock return at the $t$-th day, and $R_{m, t}$ denote the index return at the $t$-th day. The dummy variable $D_{t}$ takes value 0 , if time $t$ belongs to the prior period, otherwise, it takes value 1 . The CAPM with dummy variable is expressed as:

$$
R_{i, t}=\alpha_{i, \text { before }}+\beta_{i, \text { before }} \cdot R_{m, t}+\left(\alpha_{i, \text { after }}-\alpha_{i, \text { before }}\right) D_{t}+\left(\beta_{i, \text { after }}-\beta_{i, \text { before }}\right) D_{t} \cdot R_{m, t}+\varepsilon_{i, t}
$$

where $\beta_{i}$, is the market risk coefficient and $\varepsilon_{i, t}$ is the random error term. Besides, empirical results from Bollerslev (1986) indicated that the random error term along with a GARCH(1,1) model has a rather better fitness in practice. Thus, $\left\{\varepsilon_{i, t}\right\}$ is furthermore assumed to follow the model:

$$
\varepsilon_{i, t} \sim N\left(0, h_{i, t}\right), h_{i, t}=\theta_{i, 0}+\theta_{i, 1} \cdot \varepsilon_{i, t-1}^{2}+\theta_{i, 2} \cdot h_{i, t-1}
$$

The testing hypothesis for the market risk is set as:

$$
H_{0}: \beta_{i, \text { after }} \leq \beta_{i, \text { before }} \text { versus } H_{1}: \beta_{i, \text { after }}>\beta_{i, \text { before }}
$$

\section{Market Depth}

Sensitivity analysis of trading volumes and stock prices was investigated by Kyle (1985) via a market depth model. The market depth is defined as the maximal trading volumes which will not affect the stock price. The market depth model with dummy variable is modified as:

$$
R_{i, t}=\gamma_{i, \text { before }}+\lambda_{i, \text { before }} \cdot V_{i, t}+\left(\gamma_{i, \text { after }}-\gamma_{i, \text { before }}\right) D_{t}+\left(\lambda_{i, \text { after }}-\lambda_{i, \text { before }}\right) D_{t} \cdot V_{i, t}+\varepsilon_{i, t}
$$

where $V_{i, t}$ is a directional trading volume, defined as: If the trading is touched by the buyer, then $V_{i, t}>0$; otherwise, $V_{i, t}<0$. A small value of $\lambda$ deduces the existence of market depth. Similarly, $\left\{\varepsilon_{i, t}\right\}$ following a GARCH(1,1) model is assumed. The parameter $\lambda$ could be used to test the variability of the market depth after the warrant issuance. The testing hypothesis is set as:

$$
H_{0}: \lambda_{i, \text { after }} \geq \lambda_{i, \text { before }} \text { versus } H_{1}: \lambda_{i, \text { after }}<\lambda_{i, \text { before }}
$$

\section{Market Tightness}

Applying the published daily data of the best five bid-ask spreads information, the market tightness is measured: For the $i$-th stock, let $x_{i, \text { after }}\left(x_{i, \text { before }}\right)$ denote the daily average of the best five bid-ask spreads during the posterior (prior) period, and the parameter $\mu_{i, \text { after }}\left(\mu_{i, \text { before }}\right)$ denote the respective expectation. The parameter $\mu$ could be used to test the variability of the market tightness after the warrant issuance. The testing hypothesis is set as:

$$
H_{0}: \mu_{i, \text { after }} \geq \mu_{i, \text { before }} \text { versus } H_{1}: \mu_{i, \text { after }}<\mu_{i, \text { before }}
$$




\section{Market Liquidity}

Transaction volume is one of the best attributes to examine the stock liquidity. To avoid the firm size effect, the stock turnover rate is used to substitute the transaction volume. Let $m_{i, \text { after }}\left(m_{i, b e f o r e}\right)$ denote the average of the $i$-th stock turnover rate during the posterior (prior) period. To test whether stock liquidity enlarged is performed by the following testing hypothesis:

$$
H_{0}: m_{i, \text { after }} \leq m_{i, \text { before }} \text { versus } H_{1}: m_{i, \text { after }}>m_{i, \text { before }}
$$

\section{Empirical Analysis}

\section{The Data Sources}

From August, 1997 to December, 2007, there are nearly 5,000 call warrants on trading in Taiwan market. The call warrants which have been redundantly packed under the same underlying stock, during the research periods, are removed. After screening, there are 273 qualified call warrants and each warrant corresponds to an underlying stock. Among the selected 273 stocks, 147 stocks belong to the electronic industry, 22 stocks belong to the financial industry and the remaining 104 stocks are classified as the other industry. The warrant data are coded from TSE, and TAIEX data and stock data are coded from TEJ. TSE provides the best five bid-ask spreads information starting from January 2001. Since there were 6 warrants traded on the market before 2001, therefore, only 267 warrant data are used to conduct the tightness testing.

For each hypothesis aforementioned, the stock data are used to examine whether there is significant difference before or after call warrants issued. Firstly, the Phillips and Perron (1988) unit root test is performed to examine the stationary property of the stock return data. The results indicate that during the prior (posterior) period, 95\% (97\%) data with $p$-value are less than 5\% and the remaining $p$-values are less than $10 \%$. Therefore, stock return data are regarded as stationary. Next, the testing results of the JB statistics indicate that the normality assumption of the stock return data is acceptable during the research period.

\section{Analysis of Price, Volume and Volatility}

The impacts of warrant issuance through the market risk, depth, tightness and directional liquidity on the underlying stocks are investigated for each industrial type. Applying the CAPM to test the market risk, the hypothesis is set as:

$$
H_{0}: \beta_{i, \text { after }} \leq \beta_{i, \text { before }} \text { versus } H_{1}: \beta_{i, \text { after }}>\beta_{i, \text { before }}
$$

Among the 147 electronic industrial stocks, there are 21 stocks with $p$-value being less that $5 \%$, accounting for $14 \%$; Referring to the financial industrial stocks and the other industrial stocks, the proportions of $p$-value being less than $5 \%$, are $27 \%$ and $23 \%$ respectively. The evidences show that the warrants issuance may not efficiently reduce volatilities of the stock return. However, the increasing proportion of financial industrial stocks behaviors stronger than that of electronic industrial stocks. The result indicates that financial industrial stocks undertake per unit's market risk, the risk premiums are higher than that of electronic industrial stocks. Therefore, opportunities to invest financial industrial stocks have been enhanced.

Applying model (3), the hypothesis to test market depth, is set as follows:

$$
H_{0}: \lambda_{i, \text { after }} \geq \lambda_{i, \text { before }} \text { versus } H_{1}: \lambda_{i, \text { after }}<\lambda_{i, \text { before }}
$$

The proportions of $p$-value less than $5 \%$ are, $15 \%$ for electronic industry stocks, $9 \%$ for financial industry stocks and $13 \%$ for the other industry stocks. It is obvious that the influence of trading volumes is less in financial industry stocks. Since Taiwan stock market is the request order actuates the market, more limited orders will increase the market depth. The mentioned results indicate that call warrant issuance may possibly 
help to reconcile the deal between buyers and sellers, and thus enhance the market depth.

The market tightness is measured by the variation of bid-ask spreads, via testing:

$$
H_{0}: \mu_{i, \text { after }} \geq \mu_{i, \text { before }} \text { versus } H_{1}: \mu_{i, \text { after }}<\mu_{i, \text { before }}
$$

The $p$-values less than $5 \%$ for electronic industry stocks, financial industry stocks and the other industry stocks, are $34 \%, 32 \%$, and $21 \%$, respectively. Significant evidences indicate that the market tightness change deeper for both electronic and financial industry stocks. The bid-ask spreads get smaller, thus traders pay less transaction costs. This phenomenon will commonly occur to the more active stocks. For Taiwan stock market, the electron industry is really more detachable. Due to call warrants issuance, the un-finalized bid-ask spreads will be reduced.

Finally, testing enhancement on the stock averaged turnover rate:

$$
H_{0}: m_{i, \text { after }} \leq m_{i, \text { before }} \text { versus } H_{1}: m_{i, \text { after }}>m_{i, \text { before }}
$$

The resulted proportion increased on the turnover rate of financial industry stocks reaches as high as $55 \%$, higher than that of electronic industry stocks, being $35 \%$. After call warrants release, the underlying stocks will usually attract the investors or organization investors more attentions, thus the turnover rate will enlarge and the stock market liquidity will increase. According to the industry type, all the discussed results are shown in Table 1.

Table 1

\begin{tabular}{|c|c|c|c|c|c|c|c|c|c|c|c|c|}
\hline & \multicolumn{3}{|c|}{ Market risk } & \multicolumn{3}{|c|}{ Market depth } & \multicolumn{3}{|c|}{ Market tightness } & \multicolumn{3}{|c|}{ Market liquidity } \\
\hline Model & CAPM & & & Kyle & & & Best & ask-b & spread & Turno & r rate & \\
\hline Parameter & $\beta$ & & & Recip & al of & ness & Aver & d bid-c & spread & Avera & d turno & r rate \\
\hline$p$-value & $\mathrm{E}$ & $\mathrm{F}$ & $\mathrm{O}$ & $\mathrm{E}$ & $\mathrm{F}$ & $\mathrm{O}$ & $\mathrm{E}$ & $\mathrm{F}$ & $\mathrm{O}$ & $\mathrm{E}$ & $\mathrm{F}$ & $\mathrm{O}$ \\
\hline 0.025 & 0.14 & 0.27 & 0.23 & 0.15 & 0.09 & 0.13 & 0.34 & 0.32 & 0.21 & 0.35 & 0.55 & 0.37 \\
\hline 0.075 & 0.05 & 0.09 & 0.06 & 0.08 & 0.09 & 0.06 & 0.05 & 0.05 & 0.05 & 0.09 & 0.00 & 0.02 \\
\hline 0.125 & 0.06 & 0.00 & 0.10 & 0.05 & 0.09 & 0.03 & 0.01 & 0.04 & 0.04 & 0.04 & 0.00 & 0.05 \\
\hline 0.175 & 0.02 & 0.09 & 0.06 & 0.05 & 0.00 & 0.03 & 0.01 & 0.02 & 0.02 & 0.04 & 0.00 & 0.05 \\
\hline 0.225 & 0.04 & 0.05 & 0.05 & 0.04 & 0.05 & 0.03 & 0.00 & 0.03 & 0.02 & 0.06 & 0.00 & 0.00 \\
\hline 0.275 & 0.04 & 0.05 & 0.05 & 0.02 & 0.10 & 0.04 & 0.02 & 0.02 & 0.03 & 0.01 & 0.06 & 0.02 \\
\hline 0.325 & 0.05 & 0.05 & 0.04 & 0.04 & 0.05 & 0.04 & 0.04 & 0.02 & 0.00 & 0.02 & 0.00 & 0.04 \\
\hline 0.375 & 0.03 & 0.00 & 0.04 & 0.05 & 0.02 & 0.03 & 0.05 & 0.03 & 0.01 & 0.02 & 0.00 & 0.04 \\
\hline 0.425 & 0.04 & 0.05 & 0.05 & 0.09 & 0.05 & 0.07 & 0.05 & 0.00 & 0.03 & 0.01 & 0.06 & 0.00 \\
\hline 0.475 & 0.04 & 0.00 & 0.03 & 0.02 & 0.06 & 0.05 & 0.03 & 0.00 & 0.03 & 0.04 & 0.06 & 0.00 \\
\hline 0.525 & 0.05 & 0.08 & 0.01 & 0.03 & 0.00 & 0.03 & 0.05 & 0.00 & 0.01 & 0.04 & 0.00 & 0.00 \\
\hline 0.575 & 0.02 & 0.00 & 0.02 & 0.06 & 0.09 & 0.04 & 0.07 & 0.03 & 0.00 & 0.02 & 0.00 & 0.00 \\
\hline 0.625 & 0.03 & 0.00 & 0.01 & 0.02 & 0.02 & 0.06 & 0.01 & 0.04 & 0.01 & 0.02 & 0.00 & 0.02 \\
\hline 0.675 & 0.05 & 0.00 & 0.04 & 0.03 & 0.00 & 0.06 & 0.00 & 0.05 & 0.03 & 0.03 & 0.00 & 0.02 \\
\hline 0.725 & 0.04 & 0.05 & 0.05 & 0.04 & 0.09 & 0.06 & 0.07 & 0.02 & 0.04 & 0.01 & 0.00 & 0.03 \\
\hline 0.775 & 0.02 & 0.00 & 0.02 & 0.03 & 0.00 & 0.06 & 0.00 & 0.04 & 0.06 & 0.01 & 0.01 & 0.02 \\
\hline 0.825 & 0.05 & 0.09 & 0.02 & 0.04 & 0.03 & 0.06 & 0.01 & 0.03 & 0.05 & 0.01 & 0.01 & 0.03 \\
\hline 0.875 & 0.04 & 0.05 & 0.03 & 0.04 & 0.05 & 0.03 & 0.02 & 0.02 & 0.04 & 0.03 & 0.01 & 0.02 \\
\hline 0.925 & 0.06 & 0.08 & 0.00 & 0.04 & 0.10 & 0.00 & 0.02 & 0.04 & 0.07 & 0.02 & 0.06 & 0.07 \\
\hline 0.975 & 0.13 & 0.00 & 0.10 & 0.08 & 0.07 & 0.09 & 0.15 & 0.20 & 0.25 & 0.13 & 0.18 & 0.20 \\
\hline
\end{tabular}

p-value for Each Testing Hypothesis

Notes. $p$-values are classified into 20 groups. Each group has width 0.05 and the first column denotes the middle point of the group. $E$ denotes the electronic industry; $F$ denotes the financial industry; $O$ denotes the other industry. For each testing hypothesis, the entry denotes the proportion of $p$-values falling into the designated group under the specified industry. 


\section{Overall Analysis}

In this section, an overall testing will perform, to summarize the results shown in Table 1. If the majority of $p$-value is nearby 0 , tendency supports the alternative hypothesis. That is after call warrant being issued, the situation described by the alternative hypothesis tends to occurs. For each column in Table 1, the collected $p$-values are collected, in order to perform an overall testing. Let $F$ denote the cumulative distribution function of the collected $p$-values. The Komogorov one sample testing is applied to test whether $F$ is uniformly distributed or not. On the other hand, if the majority of $p$-value is close to 0 , then $F>U(0,1)$ should be true. Thus, the testing hypothesis is set as:

$$
H_{0}: F \leq U(0,1) \text { versus } \mathrm{H}_{1}: F>U(0,1)
$$

The test statistic is $T^{+}=\sup _{0 \leq x \leq 1}[F(x)-x]$. The larger value of $T^{+}$, supports the alternative hypothesis more confidently.

The testing results show that, after call warrants issuance, the enhancement in market liquidity to the industry is most significant, in particular, for the financial industry. Market tightness is the next significant change indicator; the averaged bid-ask spreads are significantly reduced. The increasing tendency in market risk is not very remarkable, especially, the electronics industry does not receive too much affects. The impact on the market depth is the most insignificant one. The detailed results are exhibited in Table 2.

Table 2

Empirical Summarized Analysis

\begin{tabular}{|c|c|c|c|c|}
\hline & Market risk & Market depth & Market tightness & Market liquidity \\
\hline Model & CAPM & Kyle model & Best five ask-bid spread & Turnover rate \\
\hline Parameter & $\beta$ & Reciprocal of tightness & Averaged bid-ask spread & Averaged turnover rate \\
\hline $\begin{array}{l}\text { Testing } \\
\text { hypothesis }\end{array}$ & $\begin{array}{l}H_{0}: \beta_{\text {after }} \leq \beta_{\text {before }} \\
H_{1}: \beta_{\text {after }}>\beta_{\text {before }}\end{array}$ & $\begin{array}{l}H_{0}: \lambda_{\text {after }} \geq \lambda_{\text {before }} \\
H_{1}: \lambda_{\text {after }}<\lambda_{\text {before }}\end{array}$ & $\begin{array}{l}H_{0}: \mu_{\text {after }} \geq \mu_{\text {before }} \\
H_{1}: \mu_{\text {after }}<\mu_{\text {before }}\end{array}$ & $\begin{array}{l}H_{0}: m_{\text {after }} \leq m_{\text {before }} \\
H_{1}: m_{\text {after }}>m_{\text {before }}\end{array}$ \\
\hline Industry & $p$-value $<5 \% T^{+}$ & $p$-value $<5 \% T^{+}$ & $p$-value $<5 \% \quad T^{+}$ & $p$-value $<5 \% \quad T^{+}$ \\
\hline Electron & 0.105 & 0.125 & $0.292^{* *}$ & $0.332^{* * *}$ \\
\hline Finance & $0.261^{*}$ & 0.121 & $0.271^{* *}$ & $0.500^{* * *}$ \\
\hline Others & $0.251^{*}$ & 0.088 & 0.117 & $0.330^{* * *}$ \\
\hline
\end{tabular}

Notes. For each model, the first column demonstrates the proportion of the p-value being less than 5\%. For example, there are 147 electronic industry stocks, among them 21 stocks with the $p$-value are less than $5 \%$. Thus the ratio is $21 / 147=14 \%$. The second column expresses the test statistic value: $T^{+}=\sup [F(x)-x]$, for testing $\mathrm{H}_{0}: F \leq U(0,1)$ versus $\mathrm{H}_{1}: F>U(0,1)$, where $F$ is the cumulative distribution of the collected $p$-values. ${ }^{* * *}$ attaining $1 \%$ significant level; ${ }^{* *}$ attaining $5 \%$ significant level; ${ }^{*}$ attaining $10 \%$ significant level.

\section{Conclusion}

This article discusses the influences of Taiwan call warrant issuance on the underlying stocks. Each warrant should be the first issuance on the market of a sole stock. During the research period, there is no warrant, taken the same stock as the underlying security, issued. After screening, there are totally 273 call warrants qualified. The empirical results indicate that after warrants issuance, the enhancement in market liquidity is the most promising phenomenon. In particular, for the financial industry, the significance proportion reaches 55\%, higher than that of the electronic industry being 35\%. Both the electronic and financial industry 
stocks, the bid-ask spreads significantly reduce, thus the transaction costs decline. Usually, after call warrants issuance, traders will be in long hedge position; On the other hand, based on the anticipation on stock price rising, the investors will buy stocks too. This leads to increase the market liquidity. The empirical results provide partial explanations to this phenomenon.

\section{References}

Bagella, M., \& Becchetti, L. (1998). The optimal financing strategy of a high-tech firm: The role of warrants. Journal of Economic Behavior \& Organization, 35, 1-23.

Bollerslev, T. (1986). Generalized autoregressive conditional heteroskedasticity. Journal of Econometrics, 31, 307-327.

Haddad, M. M., \& Voorheis, F. L. (1991). Initial option trading and security risk and return. Journal of Business Finance and Accounting, 18, 903-913.

Hernandez-Trillo, F. (1999). Financial derivatives introduction and stock return volatility in an emerging market without clearinghouse: The Mexican experience. Journal of Empirical Finance, 6, 153-176.

Kyle, A. S. (1985). Continuous auctions and insider trading. Econometrica, 53, 1315-1335.

Kumar, R., Sarin, A., \& Shastri, K. (1998). The impact of options trading on the market quality on the underlying security: An empirical analysis. Journal of Finance, 53, 717-733.

Phillips, P. C. B., \& Perron, P. (1988). Test for a unit root in time series regression. Biometrika, 75, 335-346.

Urrutia, J. L., \& Vu, J. D. (2000). The impact of primes and scores on the price, volatility, and trading volume of underlying stocks. Financial Practice and Education, 10, 41-51. 